\title{
EREBEA
}

Revista de Humanidades

y Ciencias Sociales

NúM. 1 (2011), pp. 157-176

ISSN: 0214-0691

\section{INSTRUCTIO FIDEI. LA ENSEÑANZA DOCTRINAL EN LOS SERMONES MEDIEVALES NAVARROS ${ }^{1}$}

\author{
Beatriz Marcotegui Barber \\ Universidad de Navarra
}

RESUMEN

En este artículo se analiza someramente el contenido de la predicación bajomedieval dirigida a las audiencias más populares de la sociedad, especialmente en su vertiente de instrucción doctrinal. Para dar cumplimiento a las disposiciones del concilio IV de Letrán, los predicadores bajomedievales se esforzaron por remediar la desatención espiritual del pueblo y conseguir que sus oyentes, en su mayor parte iletrados, comprendieran las verdades fundamentales de la Fe. Exempla, comparaciones, símiles y otros recursos fueron empleados por los predicadores en su catequesis, en un esfuerzo por dar a conocer a los fieles la resurrección y redención de Cristo, las seducciones del diablo, la salvación en el cielo o la condenación en el infierno, entre otros temas. Se trataba en definitiva de que la instrucción religiosa inspirara un comportamiento moral correcto.

\section{Palabras Clave}

Predicación popular, Navarra, instrucción religiosa, siglo XV.

Fecha de recepción: 15 de enero de 2011 Fecha de aceptación: 1 de marzo de 2011

\section{Abstract}

In this article the author analyzes briefly the content of late-medieval preaching, targeted at popular audiences, specially concerning doctrinal instruction. With the aim of enforcing the regulations of the forth Lateran council, late-medieval preachers made the effort to solve the spiritual neglect of ordinary people and to make people understand the essential doctrines of their faith. Exempla, comparisons, similes and other resources were used by preachers in their teaching of the catechism, in an effort to release the Resurrection and Redemption of Jesus Christ, the temptations of the devil, the salvation in Heaven and the condemnation in hell, among other issues. In short, preachers intended to provide people with religious instruction, so as to inspire correct moral behavior.

\section{KEYWORDS}

Popular preaching, Navarre, religious, education, $15^{\text {th }}$ century. 



\section{INTRODUCCIÓN}

Desde los primeros años del Cristianismo, la predicación se constituyó como uno de los medios más importantes para difundir el mensaje del Evangelio y anunciar el Reino de Dios por el mundo. Sin embargo, con el tiempo esta práctica se fue restringiendo al ámbito religioso o monástico, descuidando de este modo el cuidado pastoral de la comunidad de fieles. En este sentido, la celebración en 1215 del IV Concilio de Letrán constituyó un hito decisivo, pues entre otras medidas se impulsó la rectificación moral del clero y se recordó su deber pastoral de predicar y administrar los sacramentos al pueblo de Dios. Asimismo, el canon décimo de praedicatoribus instituendis obligaba a los obispos a que encomendaran esta misión a personas con adecuada formación y costumbres rectas ${ }^{2}$.

Por lo tanto, la predicación bajomedieval se caracterizó por su pretensión de volver a llevar el Evangelio a los laicos y gentes iletradas — ad populum —, lo cual exigió una adaptación del mensaje y del procedimiento oratorio a los nuevos oyentes. De esta manera, los predicadores pronunciaban sus sermones en lengua vulgar, asumiendo en ocasiones el léxico y formas de hablar del pueblo. Asimismo, frecuentemente recurrían a rimas y repeticiones y solían ilustrar sus discursos con relatos moralizantes o apelando a realidades de la vida cotidiana.

Los sermones bajomedievales tenían la doble finalidad de divulgar y hacer comprensibles los dogmas de la fe y de mover a los fieles hacia la práctica de la moral cristiana ${ }^{3}$. En este sentido, es muy significativa la definición que de la predicación dio a finales del siglo XII el maestro parisino Alan de Lille: praedicatio est manifesta et publica instructio morum et fidei, informationi hominum deserviens

1 Este artículo se corresponde con la ponencia pronunciada en el coloquio "Predicación y catequesis en el mundo medieval", celebrado en la Universidad de Navarra en 18 de noviembre de 2005. Igualmente pertenece a la investigación doctoral llevada a cabo por la autora y publicada en Instructio morum et fidei. La predicación en el reino de Navarra en el siglo XV, Pamplona, Departamento de Cultura y Turismo, 2009.

$2[. .$.$] ut episcopi viros idoneos ad sanctae praedicationis officium salubriter exequendum assumant,$ potentes in opere et sermone, qui plebes sibi commissas vice ipsorum, cum per se nequiverint, sollicite visitantes, eas verbo aedificent et exemplo. [...] Unde praecipimus tam in cathedralibus quam in aliis conventualibus ecclesiis viros idoneos ordinari, quos episcopi possint coadiutores et cooperatores habere, non solum in praedicationis officio verum etiam in audiendis confessionibus et poenitentiis iningendis ac caeteris, quae ad salutem pertinent animarum. Ed. Alberigo, Giuseppe, Conciliorum oecumenicorum decreta, Bolonia, Istituto per le Scienze Religiose, 1973, pp. 239-240.

3 ZINK, Michel, La prédication en langue romane avant 1300, París, Champion, 1976, p. 12. 


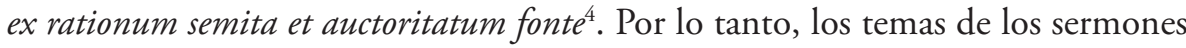
oscilaban entre los de tipo doctrinal — los destinados a la instructio fidei - y los de tipo moral —instructio morum - , que orientaban al fiel acerca del camino de salvación. Por encima de todo, el fin de la predicación era conducir al hombre hacia la salvación de su alma.

Como parece lógico pensar, los sermones predicados frente a oyentes de escasa formación insistían especialmente en cuestiones prácticas de doctrina moral. No obstante, era necesario que el fiel conociera las verdades básicas de su fe. Renunciando a toda especulación teológica, los predicadores debían esforzarse por divulgar la doctrina cristiana de manera que pudiera ser comprendida por el común de los fieles, en su mayor parte iletrados. Por lo tanto, la predicación debe ser entendida como un medio de catequesis, y su estudio puede proporcionar datos muy valiosos acerca de la mentalidad y el cuadro de creencias de la sociedad bajomedieval.

Por esta razón, en este artículo se va a prestar una atención especial a aquellos sermones o partes que incidan en cuestiones teóricas de tipo doctrinal. Concretamente se ha consultado el códice 49 de la Biblioteca de la Catedral de Pamplona, una colección de homilías copiadas en el siglo XV y de gran valor histórico. Los textos latinos originales son de mayor antigüedad, como se verá más adelante; no obstante, fueron copiados y traducidos parcialmente al dialecto navarro en el siglo $\mathrm{XV}$, lo cual parece indicar que aún entonces su contenido seguía siendo válido y útil, al menos para la lectura individual. Asimismo, el bilingüismo del manuscrito parece mostrar el avance de las lenguas vulgares — en este caso del dialecto navarro- incluso en los medios religiosos 5 .

Este manuscrito ya ha sido previamente estudiado: en 1995 Fernando González Ollé publicó un estudio y edición parcial, que cinco años más tarde fue completado y corregido por Manuel Ambrosio Sánchez Sánchez ${ }^{6}$. El manuscrito tiene unas dimensiones de 21'7 centímetros de alto por 15 '5 de ancho y para su encuadernación se empleó un pergamino que consigna el texto de un privilegio datado en $1464^{7}$. Consta de 214 folios de papel numerados con arábigos en la parte superior derecha, aunque con algunas omisiones. La caja de escritura es

4 La cita procede del primer capítulo del tratado de Lille titulado Summa de arte praedicatoria. Ed. Migne, Jacques Paul, Patrologiae Cursus completus. Series Latina, Turnhout, Brepols, 18411969, CCX, p. 111. Cit. en Zier, Mark, "Sermons of the Twelfth Century Schoolmasters and Canons” en Kienzle, Beverly Mayne (dir.), The sermon, Turnhout, Brepols, 2000, p. 329.

5 Este códice se estudia más ampliamente en el ya citado libro de la autora: Instructio morum et fidei. La predicación en el reino de Navarra en el siglo XV.

6 González Ollé, Fernando, Sermones navarros medievales: una colección manuscrita (siglo XV) de la Catedral de Pamplona, Hardover, Reichenberger Kassel, 1995; Sánchez SÁnchez, Manuel Ambrosio, "De homiliarios medievales: el ms. 49 del Archivo de la Catedral de Pamplona" en La primitiva predicación española medieval: tres estudios, Salamanca, SEMYR, 2000, pp. 41-162.

7 GonZÁlez Ollé, Fernando, Sermones navarros medievales, p. 8. 
alargada y tiene unas dimensiones de aproximadamente 15 centímetros de alto por 10 de ancho.

Se trata de una colección de 158 homilías. Como es sabido, en la Baja Edad Media coexistieron dos formas de predicación: el sermón y la homilía. El sermo modernus, también llamado artístico o universitario, se conformó a lo largo del siglo XIII en el marco de las universidades y el procedimiento de exposición que empleaba era típicamente escolástico. Sin embargo, las homilías son herederas del antiguo modo de predicar de los Padres de la Iglesia y, a diferencia de los sermones universitarios que seguían los dictados de las Artes, las homilías no obedecían a ninguna preceptiva teórica. Tomaban como base un pasaje de la Biblia más amplio y se comentaba buscando profundizar en su sentido ${ }^{8}$. Los estudiosos han señalado dos etapas en la historia de este género homilético: una primera de conformación o "edad patrística”, a la que pertenecen los textos de los Padres de la Iglesia, y una segunda etapa que se extiende de los siglos VII al XII o "edad de los homiliarios", en la que los escritos de la etapa anterior y otros de autores contemporáneos se recogieron en colecciones con la finalidad de proporcionar textos para la predicación, para la lectura personal o para la declamación pública en refectorios o durante el oficio litúrgico9. Posteriormente, en los siglos XIV y $\mathrm{XV}$ muchas de estas colecciones fueron copiadas y traducidas al romance, como es el caso del códice 49 del Archivo de la Catedral de Pamplona ${ }^{10}$.

Se pueden distinguir tres partes en el códice, identificadas en el estudio de Manuel Ambrosio Sánchez Sánchez con las letras A1, B y A2. En primer lugar, una serie de doce homilías (A1) escritas en latín y que comprende los dieciséis primeros folios. Comienza con el primer domingo de Adviento y se interrumpe tras la festividad de los Santos Inocentes. En segundo lugar, desde el folio 17 hasta el 86r, continúa otra sucesión de cuarenta y cuatro homilías (B) en dialecto navarro, que se inicia con la fiesta de la Octava de Navidad y termina con el domingo decimonoveno después de Pentecostés; las últimas cinco homilías son de sanctis. Por último, en el folio 86v comienza una tercera parte de ciento dos homilías (A2) escritas en latín y que en realidad es la continuación de la primera serie (A1) del códice, que había sido interrumpida en la Octava de Navidad. Esta última parte completa el ciclo litúrgico hasta el domingo vigésimo quinto después de Pentecostés; las últimas veintiuna homilías no están dedicadas a solemnidades en concreto, sino a ocasiones más generales, llamadas de communi, como la festividad de cualquier santo, apóstol, mártir o confesor.

8 SÁnchez SÁnchez, Manuel Ambrosio, "De homiliarios medievales", p. 93.

9 Longère, Jean, La prédication médiévale, París, Institut d'Études Augustiniennes, 1983, p. 35.

10 SÁnchez Sánchez, Manuel Ambrosio, "Vernacular Preaching in Spanish, Portuguese and Catalan" en Kienzle, Beverly Mayne (dir.), The sermon, p. 800. 
Por lo tanto, las series A1 y A2 forman un bloque homogéneo, ya que entre las dos cubren de manera exhaustiva todas las festividades del calendario litúrgico, intercalando las distintas ocasiones de sanctis. De este modo, "ofrecen un muestrario coherente y muy completo de los tres tipos de textos que debe reunir todo homiliario o sermonario que se precie: de tempore, de sanctis, de communi"11. Además, ambas están escritas en la misma lengua y con el mismo estilo. De hecho, esta serie latina debe ser considerada como un ejemplar más de los homiliarios carolingios de la escuela de Auxerre que registra Henri Barré12, conocidos como Flores evangeliorum in circulo anni. Procedente probablemente de Italia o del Sur de Francia, este homiliario es uno de los testimonios más tardíos, pues el resto normalmente oscila entre los siglos XI y XIV y, sin embargo, el de Pamplona es del siglo $X^{13}$.

En cuanto a la serie de homilías en navarro (B), en primer lugar llama la atención su colocación en medio de la serie latina, dividiéndola de este modo en dos partes (A1 y A2). No obstante, esta disposición no ha sido azarosa, pues tanto la serie B como la A2 comienzan con la Octava de Navidad. Por lo tanto, parece legítimo considerar la primera serie latina (A1) como el punto de partida o base común de las otras dos (B y A2 $)^{14}$. En segundo lugar, los textos en navarro no son originales, sino que son una traducción de un homiliario latino que por el momento no ha sido localizado. En ocasiones, parece que mantienen cierta filiación con la segunda serie latina, pero en realidad no existe ninguna relación de complementariedad o dependencia entre ambas ${ }^{15}$. En la Biblioteca Nacional de Madrid se conserva un ejemplar de las Flores evangeliorum traducido al romance - manuscrito 9626-, fechable asimismo en el siglo XV. Sin embargo, el original latino de la serie en navarro no es un homiliario de la escuela de Auxerre, si bien posiblemente se encuentre muy próximo ${ }^{16}$. De hecho, se ha localizado un homiliario en la Biblioteca Municipal de Angers con el cual el manuscrito pamplonés mantiene flagrantes coincidencias: no es éste el original del que deriva directamente, pero probablemente sea alguno emparentado con él ${ }^{17}$. En definitiva y según afirma Manuel Ambrosio Sánchez Sánchez, "las convergencias y discrepancias entre las tres colecciones - Flores evangeliorum, Homiliario de Angers y la serie en romance navarro-, apuntan a una comunidad de fuentes que será preciso deslindar con más cautela" ${ }^{\prime 18}$.

11 Sánchez Sánchez, Manuel Ambrosio, "De homiliarios medievales", p. 80

12 Ibídem, pp. 85-87.

13 Ibídem, pp. 79-80.

14 Ibídem, p. 81.

15 Ibídem, pp. 87-88.

16 Ibídem, pp. 88-91.

17 Ibídem, p. 93.

18 Thomas de Waleys (muerto en 1349), maestro en Teología en la Universidad de Oxford 
En cuanto al uso que posiblemente recibió este códice, lo más probable es que fuera el de la lectura personal. Se trata, por lo tanto, de una obra adquirida para que sirviera de consulta al clero de la época, o incluso de modelo para componer sus sermones. Como se ha explicado, originariamente las homilías habrían sido compuestas varios siglos atrás. No obstante, uno de los factores que explican la utilidad y vigencia de esos textos en el siglo XV podría ser su utilización como lectura individual, y no tanto en una predicación efectiva. Sin embargo, el códice 49 se caracteriza por la práctica ausencia de referencias contextuales a la época en la que fue escrito, de modo que los textos son fácilmente adaptables a realidades posteriores, en este caso, la del siglo XV. Asimismo, la posible utilización de este tipo de códices como objeto de lectura individual explicaría la pervivencia del género homilético, si bien se ha documentado que en algunos lugares de Italia los predicadores recurrían a la forma patrística de predicar cuando se dirigían a oyentes de escasa formación intelectual o religiosa ${ }^{19}$.

Además, el códice 49 no es únicamente una copia de un texto antiguo, sino que también contiene una traducción al navarro, que es precisamente lo que otorga valor al manuscrito. La voluntad y el esfuerzo del copista por traducir al navarro las homilías latinas evidencian un interés particular por el texto y parecen dar testimonio de su utilización efectiva. Y es que su traducción tiene un fin práctico, de agilizar su lectura y facilitar su consulta.

De todas maneras, la propia presencia del códice 49 en la Biblioteca de la Catedral de Pamplona parece evidenciar una necesidad pastoral y un interés por parte del clero del siglo XV por adquirir obras que pudieran servir de formación a posibles predicadores. Sobre todo en el siglo XIII, el nuevo impulso de la predicación ad populum generó una demanda de "instrumentos de predicación", es decir, de materiales para la formación del clero en el desempeño del ministerio de la palabra, tales como manuales de predicación o Artes praedicandi, colecciones de sermones y de exempla, entre otros. En este sentido, el reino de Navarra no fue una excepción, y concretamente la Biblioteca de la Catedral de Pamplona conserva una valiosa colección de sermones de los siglos XIII, XIV y XV. Estos códices son fuentes de enorme interés histórico, pues proporcionan información no sólo

y perteneciente a la orden de Santo Domingo, constata en el segundo capítulo de su tratado De modo componendi sermones que en algunos países como Italia los predicadores empleaban habitualmente la homilía para dirigirse a las audiencias más populares (Charland, Thomas Marie, Artes praedicandi: contribution a l'histoire de la rhétorique au Moyen Âge, París-Ottawa, 1936, p. 112). De hecho, esta práctica debió de ser habitual en Florencia (Lesnick, Daniel R., Preaching in Medieval Florence. The Social World of Franciscan and Dominican Spirituality, Athens, University of Georgia, 1989, p. 135) y también, está atestiguada en Giordano de Pisa (Delcorno, Carlo, Giordano da Pisa e l'antica predicazione volgare, Florencia, Olschki, 1975, pp. 108-109).

19 BÉRIOU, Nicole, L'avènement des maîtres de la parole. La prédication effective à Paris au XIIIe siècle, París, Etudes augustiniennes, 1998, I, p. 387. 
acerca de la espiritualidad difundida en los siglos bajomedievales, sino también sobre los métodos y técnicas empleados por los predicadores para dirigirse a la comunidad de fieles. Se desconoce el uso real que se les dio a estos códices, si bien su presencia es indicativa de un interés por adquirir obras que ayudaran al eficaz desempeño de una labor de predicación.

\section{LA TRANSMISIÓN DE LA FE A TRAVÉS DE LA PREDICACIÓN}

La predicación debe ser entendida como uno de los medios más importantes de formación doctrinal en la baja Edad Media, por la cual los predicadores proporcionaban a sus fieles los pilares básicos de su fe. Sin embargo, la liturgia y los ritos de la Iglesia también jugaban un papel importante en el proceso de formación catequética y, de alguna manera, complementario al de la predicación ${ }^{20}$. No hay que olvidar que la liturgia de la Iglesia se desarrollaba en latín y ante la incomprensión general de los creyentes. Por lo tanto, la inmensa mayoría sólo retenía los signos y rituales externos realizados por los ministros de la Iglesia ${ }^{21}$. Por ello, las distintas celebraciones religiosas suponían una ocasión para la catequesis. Ya a mediados del siglo XIII, San Buenaventura constataba esta realidad y explicaba que la predicación no era el único medio de formación doctrinal, concedía mucha importancia a los ritos litúrgicos de la Iglesia. Según decía, cuando el fiel hace la señal de la Cruz, se signa en nombre del Padre, del Hijo y del Espíritu Santo, y en este acto se puede conocer a Dios en tres personas. También, cuando asiste a las celebraciones litúrgicas, puede conocer los misterios principales de Cristo: su nacimiento, su pasión y su resurrección. Asimismo, cada ańo, cuando el fiel se confiesa ante un sacerdote es consciente de la posibilidad de recibir la absolución de los pecados 22 .

Por lo tanto, la enseñanza religiosa y doctrinal de los sermones bajomedievales se acomodaba al calendario litúrgico. De hecho, habitualmente el tema de los

20 Frecuentemente se ha denominado a la sociedad medieval como la "civilización de los gestos" (Le Goff, Jacques, La civilisation de l'Occident médiéval, París, Arthaud, 1965, p. 440). Los gestos tenían una enorme importancia en la Edad Media, hasta el punto de que constituían una forma más de expresión interpersonal y de comunicación con Dios. En el caso de los sacramentos, que San Agustín definió como sacrae rei signum o gestos de las cosas sagradas (De civitate Dei, X, 5), el ritual externo se hace especialmente relevante (Vid. Sснмiтt, Jean Claude, La raison des gestes dans l'Occident médiéval, París, Gallimard, 1990; Idem, Le geste et les gestes au Moyen Âge, Aix-enProvence, CUERMA, 1998).

21 San Buenaventura, Commentaria in III librum Sententiarum Petri Lombardi, XXV, I, III: Ad illos [articulos] enim tenentur explicite credendos, quos manifestat eis non solum praedicatio, sed etiam ecclesiasticus usus et consuetudo: sicut est de Unitate et Trinitate, quam possunt nosse ex ipso actu consignationis: consignant enim se in nomine Patris et Filii et Spiritus Sancti: sicut est de nativitate, passione, resurrectione et peccatorum remissione, quos cognoscere possunt ex ipsis solemnitatibus, quas Ecclesia celebrat, et actibus sacerdotum (Ed. Doctoris seraphici Sancti Bonaventurae... Opera Omnia, Quaracchi, Collegium Sancti Bonaventurae, 1882-1902, III, p. 544).

22 Vid. Bériou, Nicole, L'avènement des maîtres de la parole, pp. 385-395. 
sermones estaba determinado por la liturgia de cada día. Desde el tiempo de Adviento hasta Pentecostés, las grandes celebraciones de la Iglesia ofrecían la ocasión a los predicadores de iniciar a sus oyentes en los distintos misterios de la $\mathrm{fe}^{23}$.

Así, el tema central de la predicación era Jesucristo, que con su muerte y resurrección redimió al hombre del pecado y le abrió a la gracia de Dios. Este misterio es fundamental en la fe cristiana, de manera que los predicadores se esforzarzaban por conseguir que sus oyentes comprendieran y asumieran esta verdad. Precisamente, el siguiente fragmento, perteneciente a una homilía para la fiesta de la Epifanía, explica las consecuencias del pecado original y la labor redentora de Cristo. En este caso, la complementariedad entre los temas de predicación y la liturgia es evidente, ya que la fiesta de la Epifanía celebra la manifestación de Jesús como Mesías de Israel, Hijo de Dios y Salvador del mundo ${ }^{24}$ :

E saber devedes que en aquel tiempo nacio Ihesu Christo, quando Herodes regnava. E por esto lo dize que Herodes carera de muerte es llamado, que en aquel tiempo todo el mundo era en muerte. En todo el mundo, sennores, asi regnava la muerte, que ninguno non escapava del infierno, que es durable muerte. Mas quando nacio Ihesu Cristo, destruyo la muerte, asi que ninguno non va al infierno si non es por su culpa ${ }^{25}$.

El texto sitúa el nacimiento de Jesucristo durante el reinado de Herodes quando Herodes regnava - y en una época dominada por la muerte: en aquel tiempo todo el mundo era en muerte. Con estas palabras, el autor se refiere a las consecuencias del pecado original: Adán y Eva, la primera pareja humana, fueron tentados por el diablo con la posibilidad de hacerse como dioses y por este pecado fueron expulsados del paraíso terrenal y condenados al sufrimiento y a la muerte eterna $^{26}$. Desde ese momento entró el Mal en el mundo, y el hombre adquirió una tendencia natural a sucumbir ante las tentaciones del diablo ${ }^{27}$. No obstante, Dios no abandonó al hombre al poder de la muerte, y nos envió a su Hijo, que con su muerte y resurrección redimió al mundo de sus pecados. Por lo tanto, el texto sitúa el nacimiento de Cristo aportando dos referencias, una histórica y otra de índole espiritual. Sin embargo, por alguna razón, el autor asimila estas dos indicaciones e indica que Herodes carera de muerte es llamado. Tal vez, el autor buscaba establecer un contraste entre Herodes, al que califica como camino de

23 Catecismo de la Iglesia católica, 528.

24 Biblioteca de la Catedral de Pamplona (en adelante BCP), cod. 49, f. 19r.

25 "Díjose Yavé Dios: 'He ahí al hombre hecho como uno de nosotros, conocedor del bien y del mal; que no vaya ahora a tender su mano al árbol de la vida, y comiendo de él, viva para siempre’. Y le arrojó Yavé Dios del jardín del Edén, a labrar de tierra de que había sido tomado" (Gn. 3, 22-23).

26 Le Goff, Jacques (ed.), L'uomo medievale, Roma, Laterza, 1989, p. 4.

27 “¿Dónde está el que ha nacido, el rey de los judíos?” (Lc. 2, 2). 
muerte, y Jesucristo, que se definió a sí mismo como "Camino, Verdad y Vida" (Jn. 14, 6). Asimismo, los Magos se refirieron a Jesús como "el rey de los judíos"28, cargo que en aquel entonces ostentaba Herodes.

Por otro lado, el autor intentaba transmitir al lector la desesperación de aquella generación de hombres previa a la llegada del Mesías, cuyo destino era la muerte eterna del alma: ninguno non escapava del infierno, que es durable muerte. De ahí el empleo del verbo "escapar", posiblemente para persuadir de la conveniencia de rechazar el pecado y las tentaciones del diablo, que conducen a la durable muerte del infierno. Así, el autor repite insistentemente esta idea para remarcar la importancia de Cristo como salvador y redentor del mundo: Ihesu Christo destruyo la muerte, asi que ninguno non va al infierno si non es por su culpa. Con su muerte y resurrección, Jesús redimió a la humanidad del pecado y la abrió a la gracia de Dios. Cristo anunció el Reino de Dios al que está llamado cada hombre y propuso un modelo de vida basado en el amor a Dios y al prójimo. En contraposición, el diablo es la antítesis de Jesucristo, que tienta al hombre con los placeres de este mundo para conducirlo a la condenación eterna en el infierno. Por eso dice el autor que ninguno non va al infierno si non es por su culpa, pues Jesucristo con su resurrección abrió el cielo para todos aquellos que lo amaran.

Este dogma fundamental de la fe cristiana es explicado en otra homilía del códice estudiado, compuesta para el cuarto domingo después de Pentecostés. En el texto, el autor reinterpreta la parábola de la oveja perdida, que constituye precisamente la lectura del Evangelio de ese día. Se trata de una parábola que se refiere a una actividad cotidiana y muy cercana a las gentes del campo, lo cual facilita la comprensión de su mensaje:

Esti ombre que las ciento oveias tiene es entendido nuestro Seńor, que tiene muchas milarias de angeles, que antes que el nasciese, todos los ombres que eran nacidos, el infierno los sorvie e la boca del diablo. Perdio Nuestro Señor el primero ombre que el fizo, a Adan, que es entendido por la centesima oveia y dexo en el cielo los angeles e vino en esti mundo a redemir sus ovejas, que son entendidas por las animas de los ombres que eran echados de parayso. Descendio al infierno e fallo a Adam e los patriarchas e todo el humano linage, e tomolos e pusolos en sus ombros e tornolos a parayso e llamo sus amigos e dixolis: [...] "Alegrat vos con mi, que fallado he la mi oveia que avia perdido". Esto que dize que llamo sus amigos deve ser entendido por los angeles del cielo, por la oveia es entendido Adam que era echado de parayso. Dize que en sus ombros lo tomo, asi es a entender los nuestros peccados levo con el, como es scripto.

28 BCP, cod. 49, f. 51v. 
Con esta parábola, el autor explica de una manera gráfica el misterio de la encarnación y redención de Jesús. De nuevo, el objetivo del texto es insistir en la importancia radical de la figura de Jesucristo en la historia de salvación de la humanidad. Así, se dice que antes de la venida del Hijo de Dios al mundo, todos los ombres que eran nacidos, el infierno los sorvie e la boca del diablo. Es preciso llamar la atención sobre el modo de presentar al demonio como una fiera que devora a los hombres y que los recluye en el infierno contra su voluntad: el infierno los sorvie e la boca del diablo. Probablemente, con esta descripción el autor pretendía ilustrar gráficamente la desolación de la primera generación de hombres, expulsados del paraíso terrenal, privados de la contemplación de Dios y condenados irremediablemente a la muerte eterna de su alma. Asimismo, tal vez el compositor buscaba inspirar en sus lectores un sentimiento de temor que les moviera a rechazar el pecado y las tentaciones diabólicas. De hecho, tanto los sermones como la iconografía medieval representaban habitualmente al demonio como una bestia: desde el siglo XI era dibujado como un ser deforme y con atributos animales: cuernos, hocico, orejas puntiagudas, cola y, a partir el siglo XIII, con alas de murciélago ${ }^{29}$.

Según el relato, el rebaño de cien ovejas de la parábola evangélica lo componen los ángeles celestiales — tiene muchas milarias de angeles - y la oveja perdida es Adán, el primer hombre. Sin embargo, Adán sucumbió al pecado y fue expulsado del paraíso: perdio Nuestro Señor el primero ombre que el fizo. No obstante, el amor de Dios hacia sus criaturas fue tal que abandonó al resto de ovejas que le habían sido fieles y se fue en busca de la que había perdido con el objetivo de recuperarla: dexo en el cielo los angeles e vino en esti mundo a redemir sus oveias. Es decir, Dios se hizo hombre, padeció y murió por los pecados del mundo, y descendió a los infiernos para rescatar a la humanidad del poder de la muerte: $e$ fallo a Adam e los patriarchas e todo el humano linage. Y Jesús, como Buen Pastor, tomolos e pusolos en sus ombros e tornolos a parayso. En esta homilía, el autor parece insistir en el valor de la encarnación de Dios, que vino a este mundo y cargó con el pecado y el sufrimiento humano para redimir al mundo: en sus ombros lo tomo, asi es a entender los nuestros peccados levo con el. Igualmente más adelante se insiste en esta misma idea: Verdadera mente tomo nuestras enfermedades e los nuestros dolores levo con e ${ }^{30}$.

Otro tema muy recurrente en los sermones bajomedievales es el diablo. La finalidad de la predicación era la salvación del hombre, de manera que los religiosos debían advertir a sus oyentes acerca de la necesidad de rechazar el pecado, pues al final de sus días cada uno de ellos debería dar cuenta de su vida en el Juicio Final: en la fin del mundo todos veran delante el nuestro Señor, que de cada uno

29 Baschet, Jerôme en Le Goff, Jacques; Schmitt, Jean Claude (dirs.), Dictionnaire raisonné de l'Occident médiéval, París, Fayard, 1999, voz "diable", p. 263.

30 BCP, cod. 49, f. 52r. 
razon de lo que ave obrado e que reciba cada uno lo que avra merecido ${ }^{31}$. Por ello, el demonio era presentado por los predicadores como una alternativa opuesta a Jesucristo, que en todo momento intenta desviar a los hombres del camino de salvación tentándolos con los placeres del mundo. Sin embargo, los deleites que ofrece el diablo son perecederos y en nada comparables con la gloria eterna de la salvación. En este sentido, cabe destacar el siguiente fragmento de una homilía para el quinto domingo después de la Epifanía, en el que se explica la parábola bíblica de la cizaña y se advierte de las malas intenciones del demonio y de su manera de proceder $^{32}$ :

Deus es esti ombre, la simiente que sembrava era la dotrina del criador, la pieça en que sembró la buena simiente son los nuestros coraçones, el dormir que los ombres duermen es entendida la pereza que es en nos, que para mal fazer somos despiertos e para el bien somos adormidos e perezosos. El enemigo que el abri oio ${ }^{33}$ sembro es el diablo, que es enemigo de Dios e de los ombres, que viene de noche quando los ombres duermen e siembra la mala dotrina en nuestros coraçones e fázenos partir de las buenas obras e perseverar en las malas [...] De estos dos sembradores de Ihesu Christo e del diablo vos diremos como es del dia que nuestro Señor Ihesu Christo formo a Adan fasta el dia de oy, estos dos sembradores non quedan de sembrar. El nuestro Señor siembra caridat, que es buena simiente, el diablo siembra discordia, que es mala simiente, el uno siembra humildat, el otro sobervia, el uno castidat, el otro fornicio e adulterio, el uno paç, el otro guerra. El uno nos quiere levar a paraiso que regnemos con el, el otro al infierno que penemos con el. Señores, el diablo non quiere de nos pieça nin vińa, nin otro aver ninguno mas el cuerpo con el anima ${ }^{34}$.

En este texto, el autor explica que en este mundo hay dos sembradores: Jesucristo y el diablo. Jesucristo es Dios hecho hombre, el Verbo encarnado que siembra la doctrina del Padre Creador en su campo, es decir, en el alma humana: Deus es esti ombre, la simiente que sembrava era la dotrina del criador, la pieça en que sembró la buena simiente son los nuestros coraçones ${ }^{35}$. Sin embargo, el hombre no

31 Ibídem, f. 33r.

32 Mt. 13, 24-30. Jesús explicaba el Reino de los Cielos como un campo de semilla buena. Sin embargo, cuando los trabajadores del campo dormían, un enemigo sembró cizańa. Cuando creció esta mala hierba, el sembrador de la parábola decidió no arrancarla para no dańar el buen trigo que crecía a su lado, sino que esperaría hasta que ambos crecieran para segar la mala hierba y entonces echarla al fuego.

33 "Abriojos": abrojos, zarzas espinosas (Tierra Estella). "Abrojo": nombre que dan a la planta Centaurea calcitrapa (Ribera). Iribarren, José María, Vocabulario navarro seguido de una colección de refranes, adagios, dichos y frases populares, Pamplona, Diario de Navarra, 1997.

34 BCP, cod. 49, ff. 27v-28r.

35 Jesucristo es el Verbo encarnado, como dice San Juan: “y el Verbo se hizo carne y habitó 
siempre está dispuesto a hacer el bien y en ocasiones se deja llevar por la desidia, lo cual es aprovechado por el diablo para sembrar el Mal en el mundo: para mal fazer somos despiertos e para el bien somos adormidos e perezosos. De este modo, el demonio es el enemigo de Dios e de los ombres, un mal sembrador que desde el pecado original hasta la actualidad no queda de sembrar y se entromete en la viña del Señor para plantar mala simiente.

Así, ambos sembradores plantan semillas diferentes, es decir, doctrinas opuestas. Mientras que Jesús siembra la Verdad en el hombre, el demonio induce al Mal e fázenos partir de las buenas obras e perseverar en las malas. El diablo no tiene viña propia ni tampoco la desea —non quiere de nos pieça nin viña-, pues tan sólo busca la condenación eterna de los que trabajan en la viña del Señor. Por lo tanto, no sólo es el enemigo de Dios, sino también del hombre, a quien atrae con engańos para llevarlo al infierno y que penemos con el. Por eso, como se insiste en la homilía, el momento que elige el diablo para sembrar el mal es la noche, cuando todos duermen, es decir, los momentos de debilidad del hombre. Esta nocturnidad diabólica se opone a la luz de Jesús que es, como él mismo se presentó, "la luz del mundo" (Jn. 8, 12). En contraposición, Jesús siembra su doctrina en los corazones de los hombres para que dé buen fruto y participen de su Reino, nos quiere levar a paraiso que regnemos con el.

Por otro lado, llama la atención que en el texto citado se haya intercambiado el término evangélico de "cizaña" por el vocablo local de "abrioio". Probablemente, el empleo de esta expresión sea intencionado y persiga hacer más comprensible la parábola evangélica. En efecto, la sociedad medieval tenía una economía eminentemente agrícola y, por lo tanto, estaba muy habituada a encontrarse malas hierbas —o "abriojos" - en sus campos de labor. Así, las gentes sabían que el mejor modo de proceder contra estas zarzas era esperar a que crecieran, y no arrancarlas desde un principio, pues se corría el riesgo de desenraizar el trigo de alrededor. Por lo tanto, la parábola es especialmente apropiada para gentes del campo, porque emplea un lenguaje agrícola ampliamente conocido y que facilitaría la comprensión del mensaje pastoral.

Con frecuencia, los predicadores se referían en sus sermones al premio eterno que Dios tiene reservado a todos aquellos que lo amaran, y asimismo advertían de las terribles penas que sufrirían en el infierno los que perseveraran en el pecado. De este modo, los sermones tenían habitualmente un tono exhortativo que buscaba mover a los oyentes a que rechazaran el pecado y recurrieran a los sacramentos de la Iglesia para recuperar la gracia de Dios. Precisamente, la siguiente homilía para el noveno domingo después de Pentecostés incita al lector

entre nosotros" (Jn 1, 14). Es decir, es la Palabra Eterna e Imagen sustancial de Dios, que vino a este mundo para transmitir la Verdad y ser modelo de santidad: "Yo soy la Verdad, la Luz y la Vida; nadie viene al Padre sino por mí” (Jn 14, 6). Catecismo de la Iglesia católica, 459 y 479. 
a la práctica de obras de misericordia, recordando las penas que están destinadas a los pecadores:

Así como el árbol que non lieva fruto es taiado e metido en el fuego, otrosí el ombre que es muerto en pecado es condenado e metido en el fuego infernal. [...] Hermanos, tornat a vos mismos, guardat vuestras cogitaciones e vuestros fechos e pensat mucho qué árbores soes o quáles fructos fazes e pensat en vuestros coraçones estas palabras que son dichas e mayormente de esto que dize que "todo árbol que non fiziere buen fruto, taiado será e metido enel fuego" 36 . Avet pavor de esta palabra e fazet fruto de caridat e de buenas obras, serviendo a nuestro Señor, e poredes entrar en el regno celestial ${ }^{37}$.

De nuevo, el texto recurre a un símil agrícola para explicar el mensaje del Evangelio. Concretamente, el autor compara el modo de actuar de Cristo juez con el de un agricultor. Así como el hombre desecha y prende fuego a todos aquellos árboles que no dan fruto, de la misma manera Jesucristo salvará únicamente a los hombres que den frutos de caridad y de amor a Dios y al prójimo. Por ello, el autor invita al fiel a la reflexión y al examen de conciencia: tornat a vos mismos e pensat mucho qué árbores soes o quáles fructos fazes. Además, el predicador recuerda a sus fieles que el pecado no se comete únicamente con los hechos, sino también con el pensamiento: guardat vuestras cogitaciones e vuestros fechos. Como se decía en la homilía ya comentada para el día de la Epifanía, ninguno non va al infierno sino es por su culpa, de manera que el modo de vivir del hombre en este mundo es decisivo del destino eterno de su alma.

Las descripciones del infierno y de las penas que sufrían los condenados son relativamente habituales en los sermones medievales. El infierno es recreado como un lugar oscuro, donde los condenados privados de la contemplación de Dios sufren tormento eterno por sus pecados. En el anterior fragmento, el autor advierte a los fieles de que todos aquellos que no practiquen la caridad serán enviados al fuego eterno del infierno: todo árbol que non fiziere buen fruto, taiado será e metido en el fuego. El predicador explica el Juicio Final como una recolección: al igual que el agricultor desecha aquellos árboles que no dan fruto en su campo, sólo entrarán en el Reino de los Cielos aquellos que hayan dado testimonio de fe con buenas obras. Además, el religioso recuerda que así como los árboles estériles son destruidos y quemados en el fuego, el destino eterno de los pecadores es la condenación en el infierno: así como el árbol que non lieva fruto es taiado e metido en el fuego, otrosi el ombre que es muerto en pecado es condenado e metido en el fuego infernal. Asimismo, con estas palabras el autor recuerda al lector la inminencia

36 "El árbol que no da buenos frutos es cortado y arrojado al fuego" (Mt. 7, 19).

37 BCP, cod. 49, f. 57 r. 
de la muerte, que puede llegar en cualquier momento, y la importancia de estar limpios de pecado y preparados para este trance, tras el cual cada hombre tendrá que dar cuenta de su vida ante Dios. Así, la exhortación a la confesión es una constante en la predicación bajomedieval, puesto que desde el IV Concilio de Letrán todos los fieles estaban obligados a recibir este sacramento al menos una vez al año.

Junto con el fuego, otros elementos relativamente frecuentes en las descripciones del infierno son los gusanos que corroen el cuerpo del pecador, metáfora del tormento de la conciencia ${ }^{38}$, y los lloros y lamentos de los condenados. Por ello, en el texto comentado el autor exhorta al lector a temer el infierno y, en consecuencia, a cambiar de vida en servicio del Señor: Avet pavor de esta palabra e fazet fruto de caridad [...] e poredes entrar en el regno celestial.

Estas advertencias deberían de generar temor en los oyentes, si bien el fin fundamental de los discursos de los predicadores era mover a la conversión y guiar a los fieles por el camino de salvación. No obstante, de ningún modo hay que pensar que la predicación medieval empleaba este recurso del miedo a la condenación eterna como único argumento de persuasión. De hecho, con frecuencia los predicadores hacían razonar a sus oyentes y les explicaban las verdades de fe y el sentido de la doctrina moral de la Iglesia. Por ejemplo, en el siguiente fragmento, perteneciente a una homilía para el domingo de Resurrección de Jesucristo, el autor explica la resurrección final de los muertos apelando a realidades y actividades de la vida cotidiana de entonces. De hecho, el autor se adelanta a las posibles réplicas de los fieles, consciente de que la realidad de la descomposición de los cadáveres puede suponer un impedimento para creer que al final de los tiempos los cuerpos volverán a cobrar vida ${ }^{39}$ :

Señores, muchos son que dudan en el resucitamiento de la carne; quando veden la carne podrir e los uesos en polvo tornar e non creden que del polvo puede Deus fazer carne e uesos [...] Mas por quanto veden que se torna ombre en cenisa, non creden que sea ombre resucitado. Esto no es es por otra cosa si non que los miraglos de Deus son tenidos en vil ${ }^{40}$.

El autor comienza su explicación constatando la evidencia de la corrupción del cuerpo tras la muerte, lo cual dificulta la creencia en una futura resurrección

38 Hugo de San Víctor (muerto en 1114) expresa claramente esta idea en su obra De sacramentis Christianae fidei (II, XVI, V): in carne cruciabitur per ignem et in spiritu per constientiae vermem. Ed. Migne, Jacques Paul, Patrologiae Cursus completus. Series Latina, CLXXVI, p. 588.

39 "La resurrección de la carne significa que, después de la muerte, no habrá solamente vida del alma inmortal, sino que también nuestros cuerpos mortales volverán a tener vida". Cfr. Catecismo de la Iglesia Católica, 990.

40 BCP, cod. 49, f. 33v. 
de la carne: quando veden la carne podrir e los uesos en polvo tornar. De esta manera, el predicador también recuerda al lector que esta vida es efímera y que todo bien o placer de este mundo es temporal, mientras que la vida que ofrece Dios y a la cual está llamado todo hombre es eterna: por quanto veden que se torna ombre en cenisa, non creden que sea ombre resucitado. La resurrección final de la carne es una verdad de fe, y por lo tanto el primer argumento del predicador es la omnipotencia de Dios, para quien nada es imposible: esto no es por otra cosa si non que los miraglos de Deus son tenidos en vil. A continuación, el autor intenta explicar este dogma comparando la muerte del hombre con la plantación de una semilla en tierra que posteriormente da lugar a una planta. Sin duda, se trata de un símil con el que la mayoría de la población estaría familiarizada:

Mirat, hermanos, a la simiente de los frutales, como es plena de grand carga, siquier nozedo, siquier cereso o otro frutal qualquier que sea, que primera mente tenedes la simiente en las manos e en aquella sta la raiç e la fusta e la corteza e las e el fruto. [...] E que mira si nuestro Señor uesos e nervios e carnes e cabellos crea de polvo, que de una poca simiente tantas cosas faze naçer. [...] Digamos quando el ombre es soterrado, simiente es sembrada en tiera. Como de la simiente que muere nace todo esto que avemos contado, otrosi el ombre que muere tiene de nacer a su tiempo ${ }^{41}$.

El predicador compara al hombre con el árbol que crece a partir de una semilla. Así como esa simiente contiene en sí misma la raíz, el tallo, las hojas y el fruto de una planta, de la misma manera Dios uesos e nervios e carnes e cabellos crea de polvo. Sin embargo, la vida es finita y termina con la muerte, que en el hombre es, en realidad, el nacimiento a la vida eterna. Al igual que la semilla debe ser enterrada para que nazca el fruto, la muerte corporal del hombre es el tránsito hacia la nueva vida: quando el ombre es soterrado, simiente es sembrada en tiera. Esa semilla da lugar a una planta, que en el hombre es la resurrección en cuerpo y alma para asistir al Juicio Final que decidirá su destino eterno: otrosí el ombre que muere tiene de nacer a su tiempo. De modo que la muerte de un hombre justo es el principio de su vida en la gloria eterna de Dios.

A continuación y para reforzar la explicación, el autor explica a los fieles el proceso de concepción y gestación del embrión en el vientre materno, como un argumento más que prueba la omnipotencia creadora de Dios. Como se indica, Dios interviene directamente en este proceso de creación de vida:

Aún en otra guisa vos lo faremos entender: cada uno de vos, antes que fuese nacido fue en los lombos de su padre. La simiente cayda en los vientres de las madres creóse e jutóse, como la leche quando li echan el quaio, 
e de la calentura del vientre tórnase en sangre e de la sangre fázese la carne e los uesos. Aquella carne formose en miembros e fiziéronse oios, narizes e manos e los otros miembros que son en el cuerpo de cada uno ombre. Estos miembros studieron en el vientre de la muger sin vida quatro meses y medio. A cabo de quatro meses y medio, inbió Deus vida en aquella creatura e yació bivo en el vientre quatro meses e medio. Complidos nueve meses, nació en el mundo. Pues aquel seńor que todo esto faze en el ombre, ¿non podrá fazer lo que fue, que de tan neta cosa nos faze bien? Sabet que sí podra ${ }^{42}$.

Se trata de un texto sumamente interesante, por cuanto que da noticia acerca de los conocimientos médicos que se tenían antiguamente sobre el embarazo y la gestación. El autor se esfuerza por divulgar estos conocimientos, explicando de manera gráfica los fundamentos de la reproducción humana: cada uno de vos, antes que fuese nacido fue en los lombos de padre. Según parece deducirse del texto, es el esperma masculino el responsable de la constitución del embrión, que se almacena en los "lomos" del padre, es decir, en los testículos ${ }^{43}$. Una vez en el útero femenino, el semen actúa como el cuajo en la leche: la simiente cayda en los vientres de las madres creóse e jutóse, como la leche quando li echan el quaio. Por lo tanto, el autor asimila el desarrollo del embrión con el proceso de coagulación y fermentación de la leche, paso previo para la preparación del queso. Se trata de un proceso ampliamente conocido por las gentes de campo, puesto que el queso era un producto de amplio consumo en la Edad Media ${ }^{44}$. En realidad, estas ideas no son originales, sino que pertenecen a Aristóteles, cuyas reflexiones embriológicas tuvieron mucha repercusión en la medicina medieval ${ }^{45}$. De hecho, estas tesis, incluida la analogía de la leche, aparecen recogidas en el tratado De formatione corporis humani in utero, escrito en 1276 por Egidio Romano ${ }^{46}$.

Con este símil, el autor explica la formación del cuerpo del feto a partir de una simiente aportada por el hombre y que se deposita en el vientre materno. Progresivamente y con el calor del útero, esta semilla crece y se convierte en sangre, que

42 Ibídem, f. 34 r.

43 Estrictamente, el lomo o lombo es la parte dorsal del hombre entre el tórax y la pelvis, si bien parece que en este caso el autor se refiere a los testículos. Vid. Herrera, María Teresa (1996), Diccionario español de textos médicos antiguos, Madrid, Arco Libros, 1996.

44 De fácil conservación y gran riqueza nutritiva y calórica, este producto constituía un excelente complemento del alimento cerealístico base. Vid. García DE CorTázar, José Ángel, "Las necesidades ineludibles: alimentación, vestido, vivienda" en Menéndez Pidal, Ramón, Historia de España, XVI, Madrid, Espasa-Calpe, 1994, p. 18.

45 Aristóteles expresa estas ideas en su tratado De generatione animalium, I, 20, 729a; II, 4, 739b. Ed. Lours, Pierre, Aristote, De la génération des animaux, París, Les Belles Lettres, 1961, pp. $39-40$ y 69.

46 Cit. en Jacquart, Danielle; Tomaset, Claude, Sexualidad y saber médico en la Edad Media, Barcelona, Labor, 1989, p. 55. 
da origen a los huesos y los distintas partes del hombre: e de la calentura del vientre tornase en sangre e de la sangre fazese la carne e los uesos. Sin embargo, según el texto, la intervención de Dios confiriendo vida a ese cuerpo se produce a los cuatro meses y medio de embarazo: A cabo de quatro meses y medio, inbio Deus vida en aquella criatura. Hasta entonces, estos miembros studieron en el vientre de la muger sin vida quatro meses y medio. Esta idea está en relación con la llamada "tesis de la animación retardada", basada en las reflexiones filosóficas de Aristóteles y que relaciona la recepción del alma racional con la adquisición de forma humana por parte del nuevo ser. Esta tesis comienza a ser dominante en la tradición cristiana a partir del siglo VII y se mantiene hasta el siglo XVII. Santo Tomás de Aquino defiende esta teoría, atribuyendo a Dios la creación del alma humana ${ }^{47}$.

Con esta explicación, el predicador pretende demostrar la omnipotencia de Dios, que de la misma manera en que es capaz de generar vida a partir de la nada, así mismo podrá resucitar en cuerpo y alma a los muertos: aquel señor que todo esto faze en el ombre, ¿non podra fazer lo que fue, que de tan neta cosa nos faze bien? La respuesta del predicador a esta pregunta es firme, posiblemente para inculcar al lector una fe fuerte en Dios: Sabet que si podra.

\section{Consideraciones Finales}

Parece claro que los predicadores bajomedievales se esforzaron por difundir y divulgar las doctrinas básicas de la fe. Puesto que la mayor parte de la sociedad era iletrada y carecía de formación religiosa, los religiosos procuraban explicar los misterios de la fe católica por medio de narraciones y comparaciones con la vida cotidiana. Este esfuerzo por instruir a los fieles tenía un sentido práctico de mover a la conversión y de incitar un comportamiento moral correcto que les condujera a Dios. Por ello, los predicadores también aclaraban el sentido de la doctrina moral de la Iglesia, explicando la finalidad y conveniencia de adoptar determinadas actitudes y costumbres. En este sentido, es significativa la definición de sermón que recoge fray Martín de Cordoba, un fraile agustino de siglo XV de quien se conserva un Ars praedicandi en la Biblioteca de la Catedral de Pamplona: sermo est oratio informativa ex ore predicatore emissa, ut instruat fideles quid credere, quid agere, quid cavere, quid timere, quid sperare debeant ${ }^{48}$. Es decir, el sermón es un discurso pronunciado por el predicador para instruir e informar a los fieles acerca de lo que debían creer, lo que debían hacer, lo que debían temer y lo que debían esperar.

47 Corpus igitur hominis formatur simul et virtute Dei quasi principalis agentis et primi, et etiam virtute seminis quasi agentis secundi: sed actio Dei producit animam humanam, quam virtus seminis producere non potest, sed disponit ad eam. Ed. Marc, Petro; Pera, Ceslao; Caramello, Petro, Santo Tomas de Aquino, Liber de veritate catholicae fidei contra errores fidelium seu Summa contra gentiles, Roma, Marietti, 1967, p. 256.

48 Ed. Rubio, F., “Ars praedicandi de fray Martín de Córdoba” en La Ciudad de Dios, 1959 (172), p. 330. 
Por lo tanto, el sermón debe ser entendido como un medio fundamental de formación, empleado hábilmente por la Iglesia medieval para proporcionar a sus fieles los conocimientos y actitudes conducentes a la salvación de sus almas. Como se ha visto, la liturgia jugó un papel esencial en ese proceso de formación de la comunidad de fieles. En principio, la predicación fue una actividad desmarcada de la liturgia medieval, si bien los sermones se basaban y explicaban la lectura del Evangelio. Así, la catequesis de los sermones seguía el ritmo de los ciclos litúrgicos de la vida de Jesús.

Por lo tanto, el tema central de este tipo de sermones era Cristo, que es Dios encarnado y que con su muerte y resurrección redimió al hombre del poder del pecado. Por otro lado, los predicadores advertían a los fieles acerca del diablo, un ser que se opone a Dios y que tienta al hombre con los placeres mundanos con la única finalidad de conducirlo a la condenación eterna en el infierno. El comportamiento del hombre en esta vida es determinante del destino eterno de su alma después de su muerte, cuando cada cual deberá rendir cuentas de sus actos ante Dios. Por ello, muchos sermones se detenían en recrear las penas del infierno, con la finalidad de atemorizar a los oyentes y así persuadirlos de la conveniencia de alejarse del pecado. De esta manera, el infierno entraría dentro de la categoría de "lo que hay que temer" — quid temere —, el diablo, en la de "lo que hay que evitar" — quid cavere—, y el paraíso, en la de "lo que hay que esperar" — quid sperare-. En efecto, en los sermones bajomedievales son relativamente frecuentes las descripciones del Cielo, como un lugar de gloria y felicidad eternas que los sentidos del hombre son incapaces de explicar o imaginar siquiera y que disfrutarán todos aquellos que amen a Dios.

En definitiva, una de las características fundamentales de los sermones bajomedievales es la sencillez de su mensaje. Lejos de las especulaciones teológicas, los predicadores seguían un estilo concreto y recurrían con frecuencia a anécdotas y comparaciones con la vida ordinaria. De hecho, los textos estudiados del códice 49 de la Catedral de Pamplona parecen dar buena muestra de ello, si bien fueron compuestos varios siglos antes. Sin embargo, este homiliario fue copiado y traducido al dialecto navarro en el siglo XV, lo cual parece indicar que sus textos todavía resultaban útiles, al menos como instrumento de formación o para la lectura personal. En ese sentido e independientemente del uso real que recibió el manuscrito, sus textos pueden ser orientativos acerca del mensaje religioso transmitido por los predicadores del siglo XV y que posiblemente lo emplearon como obra de consulta. 
